\title{
STUDENTS' OPINIONS ABOUT THE SUBJECT OF SECURITY EDUCATION IN UPPER SECONDARY SCHOOLS
}

\author{
Barbara DRAPIKOWSKA, PhD \\ War Studies University \\ Faculty of National Security \\ b.drapikowska@akademia.mil.pl
}

\begin{abstract}
The article is empirical and constitutes a qualitative analysis of students' attitudes towards the implementation of the subject of Security Education in upper secondary schools to which they attended. The research attention was focused on the form of conducting classes, issues raised on the subject, assessment of their usefulness and proposals for improvements presented by students. The self-assessment of self-attitude towards the subject and level involved in the acquisition of the core curriculum was also presented.
\end{abstract}

Keywords: Security Education, teaching process in upper secondary schools, qualitative research.

\section{Introduction}

The beginnings of the subject Security Education in practical pedagogy could be traced back to the 1920 s. Then, by virtue of the decision of superior educational institutions, a paramilitary training course was introduced in post-secondary schools. Its goal was to prepare the youth for military service in in the event of an armed conflict. Assumptions of the subject, as well as the name itself, have evolved over the last decades (Odziemkowski 1996, p. 99). In the 1960s, the name 
was changed to Defensive Approach, and its main goal was to develop habits in in the event of an attack with the weapon of mass destruction. In a limited range of content, the subject was also useful in preparing for the main military service (Falkowski 2016, p. 66).

The subject of Security Education is an element of the core curriculum in teaching in primary and secondary schools. Its essence is the transfer of content that is important for security, both in the individual and social dimension. In an individual perspective, the issues assimilated within the course are to help students take care of their own safety. For this purpose, it is expected to develop the ability to take action in a situation of threat to the life and health of the individual (Pieczywok 2012). In turn, the social dimension concerns the ability to use the transmitted content for safe functioning in social groups such as family, friends, local community and the state. Their proper transfer, as well as appropriation, seems to be important in the education process of people standing at the threshold of adulthood. Moreover, the aim of Security Education is to shape students' positive attitude and prepare for contemporary challenges to security that range from economic, political, social to environmental threats (Domalewska 2017, p. 4).

The aim of the article is to present the opinions of high school graduates on the subject of the subject of Security Education. The achievement of the adopted assumption required solving the research problem formulated in the form of the following question: What is the attitude of upper secondary school leavers towards the implementation of the subject Security Education in educational institutions, which they attended as students? Based on the main problem, specific issues including specific issues were specified:

1. What is the implementation of the subject Security Education in secondary schools?

2. What issues, according to students, were needed and interesting, and what are unnecessary?

3. What was the students' approach to the subject, as well as the attitude of the teacher?

4. What changes, according to the respondents, should be introduced in the implementation of the subject?

The article has an empirical character and is based on induced sources obtained in the course of own research. It uses qualitative research methods carried out 
using the free interview technique conducted among 40 students of the first year of bachelor studies in the field of Management and Command at the Faculty of Management and Command at the War Studies University. As a result of the research, non-standardized statements on the subject were obtained, which confirm the obtained cognitive effects presented in the individual components of the article. Each of the questionnaires received symbols from W1 to W40, which are always given when respondents' statements are quoted.

\section{Security Education in the core curriculum in secondary schools}

The necessity to engage in activities for security is one of the basic obligations of each citizen, imposed by the Constitution of the Republic of Poland and the Act (art. 85) on the Universal Defense Obligation (art. 1). The fulfillment of this obligation in the case of children and adolescents consists in the completion of education and practice in matters related to broadly understood security.

Security Education belongs to general subjects for which only the basic scope is provided. At least 30 teaching hours are allocated for the implementation of classes in each school year ${ }^{1}$. In accordance with the adopted core curriculum, the main objectives of the educational process on the subject of Security Education include knowledge of the state's defense structures, preparation to behave in an emergency situation and mastering the first aid principles. These goals have been translated into specific teaching content that can be generalized to the following categories:

- structure and principles of the security system functioning;

- military and non-military subsystem in the security structure;

- threats during peace and war;

- first aid in an emergency.

1 The core curriculum of the subject Security Education, the fourth educational stage: high school - only the basic scope (https://men.gov.pl/wp-content/uploads/2011/02/8c.pdf).

2 The implementation of general subjects included in the core curriculum in the basic scope and / or in the extended scope in the general secondary school (https://men.gov.pl/pl/zycieszkoly/ksztalcenie-ogolne/ramowe-plany-nauczania). 
According to the recommendations of the Ministry of National Education, the implementation of the core curriculum is to bring tangible benefits in practical life. In other words, students should have a defensive adoption and develop skills in the field of behavior in crisis situations. Therefore, it is recommended to organize specialized training camps during the summer and winter holidays (Regulation of the Minister of National Education of 14 June 2017 amending the regulation on the manner of implementation of Security Education).

It should also be borne in mind that Security Education is also taught in the extended profile at the stage of secondary education. In practice, it is implemented in uniformed classes, which in Poland enjoy growing popularity among young people (Urych 2016, pp. 112-134, Urych 2017a, pp. 21-47, Urych 2017b, pp. 148-177).

\section{Content falling within the scope of the subject in the assessment of the subjects}

One of the issues raised in the study was the assessment of content falling within the core curriculum in the subject Security Education. The surveyed students were asked to assess the usefulness of the issues discussed in everyday situations. Undoubtedly, they considered the most useful principles of behavior in an emergency and first aid. Respondents were convinced that this is information that every person should have. First aid classes were also those that they believed to have stuck in their memory until today. Confirmation is selected statements of the respondents obtained during the conversation on the most useful issues from the subject:

- "In my opinion, the most important and extremely useful issues were the first aid, but also the behavior and manner of operation in life-threatening situations or any kind of accidents and possible dangers" (W6);

- "Useful is the CPR, because the need to give first aid to a first-class student is a more probable event than the use of chemical, biological or other weapons" (W14);

- "The most useful issues discussed on this subject were information on providing first aid, self-defense, coping in health emergencies. Reactions to cuts, protection 
of wounds - that one is not allowed to take out a foreign body driven into any part of the human body, starting with a deeper needle penetration" (W20);

- "[...] First aid is the only thing I remember. However, I think it is very good that I could learn it because we never know when such things can affect our life or someone's life" (W28);

- "First aid is the most useful issue. Each of us should be able to help another person in a situation of health or life threat. [...] and our knowledge on a given topic can save someone's life" (W32).

However, some of the contents, according to the research, are unnecessary in the Security Education classes. Among these issues can be distinguished a number of theoretical issues regarding the functioning of individual state institutions, definitions and types of weapons. What is more, according to the respondents, they did not need to teach behaviors used in the course of military service, e.g. drill. The students spoke about the unnecessary issues raised on the subject of Security Education in the following words:

- "[...] I consider the basics of drilling unnecessary, it was not a military school" (W3);

- "I think that it was totally unnecessary to devote about three lessons to what tasks are performed by specific uniformed services" (W22);

- "[...] in my opinion, it was not necessary to learn definitions by heart, such as what health is" (W25);

- "In my opinion, completely unnecessary were classes, on which we learned signs on lorries carrying various types of loads, including dangerous ones. These are the corresponding symbols and numbers for the categories of cargo. The lessons teaching us military grades were also unsuitable" (W27);

- "[...] classes on the theory itself, such as military ranks, or on the transport of dangerous substances were boring and unnecessary in my opinion" (W37).

Classes regarding first aid rules, according to students, were not only the most useful, but also the most interesting among the issues discussed. The exercises on the shooting range, as well as all forms of group classes and practical implementation of the issues from the core curriculum were also considered interesting elements of the subject. The following examples of quotes seem to confirm this statement: 
- "It was interesting to follow the shooting range, the scope of preparation, and service of the weapon. Films related to the use of animals as helpers in the fire service, police, etc., often foreign" (W5);

- "Interesting were practical classes, we once had the chance to train various types of dressing on mannequins, it was also interesting that in the classes we had the opportunity to watch various props related to military, e.g. masks" (W23);

- "I think that this way of passing knowledge [practical] is definitely easier to absorb and just more interesting. Pure and dry theory definitely does not speed up this process. Each topic or most of themes (...) can be presented in an interesting and unusual way, even non-standard" (W28);

- "One of the interesting was the translation, what happens in the case of choking, etc. How important is the right help in this type of cases. The explanation by the lecturer that if we fail to help, it is not our fault - it is important that we tried" (W29);

- "The question that stuck in my memory is the first premedical aid that allowed me to pass the exam and receive the certificate of a younger rescuer" (W34).

In turn, the issue of various elements discussed purely theoretically was not sufficiently interesting. Students pointed out that this way of acquiring knowledge is the least useful for them. This is confirmed by the statements cited below:

- "Boring was all kinds of theory, practical classes were always full of information, but often fun and on the example it was much easier to understand the given issue" (W10);

- "Boring - types of weapons, legal regulations, humanitarian law, strategic goals of the Polish security policy" (W14);

- "[...] The subjects of the Armed Forces of the Republic of Poland were boring" (W21);

- "Boring issues were purely theoretical, like learning about the obligations of citizens and state authorities" (W33);

- "Boring and it was terribly all kinds of theory" (W39).

The student's conviction that they can use the acquired knowledge in everyday life is the best proof of the practical usefulness of the issues discussed. However, this applies only to matters related to first aid and dealing with a traffic accident. These issues in the opinion of the respondents can be used by them in different situations, as the following statements convince: 
- "In the current situation, this knowledge is very valuable due to the fact that as a volunteer at Przystanek Woodstock ${ }^{3}$ I use it in practice. Thanks to this, I understand the organization of the festival and its course much more. This helps even in the excuse of people coming to the festival why something is happening like this and not otherwise" (W2);

- "As much as you know, though it may be somewhat trimmed, it is useful. We live in a world of threats lurking at us at any time, current terrorist attacks, but also considering that I am a driver and accidents happen, also first aid can save someone's life" (W6);

- "Yes, in emergency situations I will not be a passive observer of events, I only know how to react. I have no fear that the situation will overwhelm me. I know that everything is not my strength, but every attempt at help counts. The worst thing you can do is panic" (W13);

- "Only when it comes to first aid. The rest, as I said, I do not remember. Since then, he feels more confident, seeing somebody needing help - if I can call it that. I think I have gained courage and I know what to do and how to help someone without harming myself, myself or anyone else" (W28);

- "Content carried out on this subject, I am talking about providing help, no doubt you can use it in practice, what cannot be said about other subjects in high school" (W37).

Therefore, recognition deserves awareness of the usefulness of the issues discussed, as well as their relevance in the situation of everyday life. As can be deduced from the above statements, students estimate that they have knowledge about the rules of behavior in a situation requiring assistance to victims.

\section{The form of the subject realization and their own involvement in the opinion of the respondents}

According to students' messages, in their upper secondary schools, classes in the field of Security Education were implemented both in theoretical and practical

3 A Polish rock music festival. 
terms. Practical exercises, as could already be deduced from previous statements, concerned issues related to first aid. Some of the respondents also indicated classes at the shooting range. A lot of respondents, however, took the position that they constituted a smaller part of the implementation of the educational process. The students' statements presented below are intended to confirm this statement:

- "Classes were divided into three stages. The first, as a basis, was theory. Then we went through a series of exercises while learning self-defense, to finally indulge in the most enjoyable exercises, which were shooting at a range of weapons. All these classes were obligatory" (W2);

- "Unfortunately, classes were conducted only in the theoretical form, the only practice that we had was first aid, evacuation" (W6);

- "We had several practical tasks, such as first aid on a mannequin, shooting at a shooting range or school evacuation simulations" (W9);

- "There were field exits and outdoor exercises. I think that this is a great opportunity to break the routine of classes in the benches" (W13);

- "Yes, there were practical classes, thanks to which the whole group was active in the classroom and interested and also focused" (W30).

In each educational process, one of the key aspects is the attitude of the teacher. The subject of Security Education is not an exception in this regard. Particularly noteworthy is the fact that the respondents were convinced of the key role of the teacher and the influence his person has on their own attitude towards the subject. The students also pointed out that the attitude of the teacher is very important when it comes to their involvement in learning as well as the implementation of practical tasks. In their opinion, the teacher should pay attention to the implementation of the practical dimension of the classes, as well as be able to be interested in the content being taught. The respondents argued about their opinions in the following words:

- "The role of the teacher, who spent his previous years in police service, is of great importance here. His knowledge, manner of expression, attitude were very impressive" (W2);

- "In the first school, the teacher paid a lot of attention to first aid, so we had a lot of practical classes, where we had to dress a wound of all kinds. We got a description of the situation, the accident and we had to play the whole scene, including the order when to call an ambulance, how to ask the wounded person or is conscious, etc." (W3); 
- "The attitude of the teacher was really commendable. The teacher was about 50 years old, he taught the subject for a long time, he used practical techniques of learning. He was a very honest man, he judged us sternly, but fairly. He was able to put five ones on one person who was not prepared or was not well prepared, at the end of the subject anyway they had a minimum grade 4 . The teacher could ridicule someone in front of the whole class if he caught smoking in a public place, not in a smoking room or someone who did not change shoes and spread mud all over the school. He always supported various charity events, organized picnics, helped children from orphanages and also encouraged us to do so, we could bring in chalk, toys and school supplies for children for partial grades in this subject. Quite a direct exchange, but it did not bother anyone for years and everyone agreed, other teachers also" (W20);

- "The object was run by a man of 60 , who in the past had contact with the army, information he gave us, he could convey in an interesting way, he had a good approach to students, because pass was practical, and the theory only at the end we had a test" ( W23);

- "Rather, it was a man with a passion who could attract students, but practical classes were often carried out in addition to typical theory. He often explained the problem with practical-life examples" (W24).

Due to the fact that many statements indicated a large role of the teacher in the process of upper secondary education, the study also asked about the assessment of its own leaders in this respect. The respondents' opinions were divided, however, they indicated a high dependence in the scope of perception of the entire teaching process from the attendant's attitude. The reports of the respondents assessing the high level of teaching and the attitude of the teacher have been presented above. In turn, other students who had reservations about their teachers in this matter expressed themselves in the following words:

- "I remember for sure that the subject promised to be interesting. We had learn to use firearms, which was easier because there was a shooting range in our school.However, this was not realized. Classes ended in a seat in a small room. At the beginning I was curious because the subject, as I said, promised to be interesting, but I got bored very quickly. I believe that the really needed information about the content of this subject has not even been touched upon" (W1); 
- "It could be a really useful item, but I have the impression that teachers often either downplay or make it out of the blue as a difficult and demanding subject. It seems to me that it should not be evaluated because it often demotivates us." (W4);

- "Yes, I think that if an education for safety teacher was different, I would definitely get more from these lessons" (W21);

- "From what I associate, it is rather the activities to be drummed, some papers probably were. It's not nice for me. I definitely belonged to a group of people uninterested in the activities or issues raised. The exceptions were first aid exercises. We practiced on the mannequin and on each other different methods, ways, techniques of first aid" (W28);

- "The leader was more focused on making the class quiet. We have not completed all the issues. But the most important thing in my opinion was done. [...] In my case the most important thing is that there should be such a guide who will interest the students and explain everything in a calm way, and not so that we were simply afraid of him. The subject should be more focused on practice than theory" (W29).

Students during interviews were also asked to evaluate their own commitment to learning the subject and the approach to its implementation. Some of the respondents assessed their engagement highly. In the case of some, it was related to the desire to obtain a high average, while in others it was related to the interest in the issues discussed and an interesting way to conduct them. Not without significance was also the awareness of the possibility of using the issues discussed in everyday life, which concerns in particular the rules of first aid. Below are the statements for the exemplification of this thesis:

- "There were several issues related to my plans for the future. Some were interesting, but so for general knowledge. However, I think that everyone should know the issues related to the first aid" (W13);

- "In high school, I was rather learning all subjects, I always had a grade average of about 4.50, I tried to do this as well. I liked to walk on it, it was often funny. With such an object, it was easy to raise the average, because for good grades, plus child support, you could have 6 at the end. In addition, nobody else taught us self-defense, which was a valuable experience" (W20); 
- "I applied myself to a large extent due to the fact that the subject was conducted in an interesting way and the issues allowed to learn the methodology of dealing with crisis situations, often encountered by an ordinary person" (W24);

- "I went to a high school uniform, which is why items like education for safety were very important to me. The complement to this item was typical first aid, the finale of which was to obtain a rescuer certificate. To learn from these subjects I have always been committed to helping people in my life" (W32);

- "I approached the subject with commitment, because I know that the issues that were implemented would be useful in my everyday life" (W34).

It should be admitted, however, that the majority of the surveyed students admitted that their involvement in the subject was not at a high level. This approach resulted from many factors, such as the attitude of the lecturer, the boring form of conducting them, lack of personal interest in the subject. They talked about their subjects in the following words:

- "I wanted to learn first aid in order to always have something to do in a given situation. I treated the rest as a development of knowledge, although when the topic I thought was useless like cramming military and police degrees, I was thinking only to include a card and have peace" (W3);

- "It was, unfortunately, a 3-level stage - learn, pass, forget - but the big plus is that the issues implemented in high school to some extent, even the smallest, useful for my studies" (W6);

- "If I was interested in the topic of the classes, I tried to remember him as well as possible, put in as much work as possible. It was not difficult, because it mostly involved practical classes. On the principle of learning and forgetting, I approached purely theoretical classes. This attitude was also influenced by the behavior of the teacher who did not encourage to deepen his knowledge in this area" (W27);

- "Definitely pass and forget, however it sounds. And seriously speaking, I'm definitely not an advocate of running classes casually, i.e. simply to "whine" and that's it. Exercises in which we could actively participate were decidedly more interesting" (W28);

- "[... I have approached interesting and practical issues with enthusiasm, while" patting "rules - forging, counting, forgetting" (W33). 
The above statements allow the conclusion that the surveyed students showed greater commitment during the acquisition of issues assessed by them as useful in everyday life. Undoubtedly, the forefront in this area was the provision of premedical help and behavior in the situation of witnessing an accident or other sudden threat.

Proposals for changes in the core curriculum in the opinion of the respondents. During the survey, the respondents were also asked for suggestions as to possible changes to the current core curriculum. In their opinion, changes should be made to increase the number of practical classes, at the theoretical cost. In the opinion of the respondents, the practical approach to the issues discussed is more purposeful and affects their further life - it gives knowledge about behavior in different situations. In addition to a different number of hours, students also proposed more projects outside the school - mainly trips to institutions operating in the area of security and activities at the shooting range. This thesis can be confirmed by quoting their statements obtained during the talks on improvements:

- "Do not teach people unnecessary things, such as what the guards do, what steps they take in the event of an accident, we should only be able to call this guard and that much" (W7);

- "More practice - scenes, simulations. The dry theory does not stay in mind. I remember these general things mainly thanks to scenes or practice" (W12);

- "There should be more practice in the program. It should be pointed out how the use of a particular type of weapon affects a human being and how to defend against it, instead of making students memorize the classification of weapons" (W14);

- "Dedicate more time to practical classes, instead of listening to the tasks of uniformed services, e.g. fire brigade, go to a specific unit and see how it all looks" from the other side" (W22);

- "More interesting things combined with practice to be able to use them better in our lives. The theory itself is not able to prepare us for life, therefore, instead of the overload of theoretical knowledge, there should be more tasks to gain practical knowledge" (W24).

Most changes, however, concerned first aid classes. Students were in favor of changing the form of conducting classes, as well as increasing the hours provided for this subject. Confirmation of this statement are the statements cited below: 
- "In my opinion, practical first aid classes should be repeated regularly, and not done as a block, a series of classes week after week, because it ends so that you remember what to do, and when you go to the next chapters, you systematically forget this knowledge and remember only the safe position and not to remove the foreign body from the wound, and you forget, for example how many afflictions and how many breaths. First aid classes should be spread over the whole year and implemented, e.g. every month or two weeks and rely on repetition of knowledge and learning the next topic" (W3);

- "Professional first aid courses should be introduced, thanks to which you will be able to obtain a certificate proving that we are able to help people injured in accidents or other incidents. There should be exercises to learn how to properly provide information about a traffic accident or other incident so that the services are easier to locate and shorten the waiting time for them. Classes should be conducted in a practical way and not purely theoretical" (W27);

- "Considerably more emphasis on first aid and practical activities that are useful in life. I think that each of us, being in a situation threatening his life, would like another man to help us. And many people simply cannot do the simplest lifesaving activities" (W32).

Proposals for changes also concerned other educational elements. These include introducing additional program content or changing the number of class hours. This particularly applies to self-defense issues, which, according to students, could not only make classes more attractive, but also bring practical benefits in everyday life. In order to exemplify the above statement, selected statements of the respondents were cited:

- "It is worth introducing or expanding self-defense classes within this subject. Then we have the opportunity to learn something new and unprecedented. And thus boring classes in the classroom become much more attractive "(W2);

- "There were very few hours from this subject" (W11);

- "[It should] Cut the program, but take it seriously to learn how to react in emergency situations, so that every important issue will be realized until all students have mastered it" (W26);

- "I think that there should be self-defense activities, that would help us to ensure our everyday safety, in a dangerous situation" (W33);

- "I think it is important to know how to behave, if someone attacks us in a dark alley, this subject should be taught first" (W40). 
The above statements provide the basis for concluding that the subject of Security Education was positively perceived by students and assessed as useful. Attitudes different from this position were caused by individual factors, which included elements such as the approach to education at that time and the attitude of the lecturer.

\section{Conclusions}

The aim of the article was to present the results of research on the opinions of current students - upper secondary school leavers on the subject of the subject Security Education in schools to which they attended. The achievement of the adopted assumption was connected with solving the main problem brought to the detailed issues presented in the introduction. As regards the first specific problem concerning the method of implementation of the subject, it was agreed that according to the core curriculum the subject is implemented in the 30-hour period in the school year through theoretical and practical classes. The former deal with issues related to the functioning of the state security system and threats that may occur in the contemporary social reality. On the other hand, practical classes oscillate around issues related to providing premedical help to people injured in various types of everyday accidents and communication events.

In the search for solutions to further problem issues, qualitative research was conducted among students. In reference to the second detailed problem related to the assessment of content carried out during the course, it was determined what issues are assessed as useful and interesting, as well as unnecessary or uninteresting. To the group of the first students, they included practical classes in the implementation of the premedical aid principles, which in their opinion should fulfill the mental content of each person. Unnecessary issues were of a theoretical nature and were associated with the definition of the functioning of the state security system.

With regard to the third specific problem regarding the students' approach and leading to the implementation of the core curriculum, a large link was established between the two issues. Students addicted to their attitude towards learning and involvement in classes from the attendant's attitude. In the case of classes assessed 
as interesting, they paid more attention to the acquisition of the material. In turn, in cases where the lecturer did not present a good example in their opinion, they also reflected this attitude in their own approach.

Referring to the fourth specific problem concerning changes, which according to students should be introduced in the current core curriculum, it should be noted that the respondents postulated changing the center of gravity of the course in a more practical than theoretical direction. In their opinion, a practical examination of the theory possessed to a greater extent may contribute to the permanent acquisition of knowledge, and thus a better use of it in everyday life.

In conclusion, it should be emphasized that the respondents were aware of the importance of the content provided for this subject. Their statements indicated that their skills are an important aspect of human functioning in society, because they allow for helping the needy, protecting one's own person, as well as minimizing the negative effects of random events that may be theirs.

Based on the research carried out, several applications can be made. First of all, students paid more attention to the acquired material if they found it interesting, as well as useful socially. This in turn allows you to suppose that the current scope of the subject could be broadened to include issues that are possible practical implementation. As examples, you can give deepen issues of premedical help and self-defense. Second, current the curriculum can also be made more attractive through additional activities such as visits to the commands of selected law enforcement services, public institutions, military units, emergency services. Thirdly, due to the large relationship between students' attitude towards the subject, as well as the person teaching - the teacher, you can be tempted to notice that this subject should be implemented by people who have practical contact with entering issues in its scope. Among them you can name ex-soldiers, policemen, firefighters, paramedics, who have experience they could complemented with a pedagogical aspect, which allows even studying postgraduate in Security Education. Such a solution would be beneficial both for students expecting practical knowledge, as well as former officers after leaving the service. 


\section{References}

Act of November 21, 1967 on the Universal Defense of the Republic of Poland, Journal of Laws of 2004 No. 241, item 2416.

Constitution of the Republic of Poland of 2 April 1997, Journal of Laws of 1997 No. 78, item 483.

Domalewska, D., 2017. Approaches to studying across culturally contrasting groups: Implications for Security Education. Security and Defence Quarterly, 3(16), 3-19.

Falkowski, Z., 2016. Outline of the problem of defensive education of youth in the years 1946-1990. In A. Skrabacz, I. Urlych, L. Kanarski (eds), Uniform classes from theory to good practices. Wydawnictwo Akademii Obrony Narodowej, Warsaw.

https://men.gov.pl/pl/zycie-szkoly/ksztalcenie-ogolne/ramowe-plany-nauczania [Accessed 19 Jan 2018].

https://men.gov.pl/wp-content/uploads/2011/02/8c.pdf [Accessed 17 Jan 2018].

Odziemkowski, J., 1996. Army and society II Republic of Poland. Bellona, Warsaw.

Pieczywok, A., 2012. Edukacja dla bezpieczeństwa wobec zagrożeń $i$ wyzwań i zagrożeń wspótczesności. Wydawnictwo AON, Warsaw.

Regulation of the Minister of National Education of 14 June 2017 amending the regulation on the manner of implementation of Security Education, Journal of Laws of 2017, item 1239.

Urych, I., 2016. Military class in Poland - experiences and perspectives. Security and Defence Quarterly, 2(11), 112-134.

Urych, I., 2017. Students of military classes concerning selected aspects of Poland's national security. An empirical study. Security and Defence Quarterly, 4(17), 21-47.

Urych, I., 2017. Values of military-grade students - research results analysis. Zeszyty Naukowe ASzWoj, 4(109), 148-177. 